\title{
Rolling Contact Fatigue and Static Compression Deformation of UHMWPE thrust bearing in water
}

\author{
Masahiro Inagaki ${ }^{1}$, Naoki Fujimura ${ }^{1}$, Koushiro Mizobe ${ }^{1}$, Katsuyuki Kida ${ }^{1, a}$ and Yuji Kashima ${ }^{2}$ \\ ${ }^{1}$ University of Toyama, Gofuku 3190, Toyama, 930-8555, Japan \\ ${ }^{2}$ Kashima Plastic Bearings Corporation, 2-9-21 Himesato, Nishiyodogawa-ku, Osaka, 555-0025, Japan
}

\begin{abstract}
In this study, the rolling contact fatigue tests were performed in order to investigate the effect of thrust load on life of UHMWPE bearings. Furthermore, the static compression tests were performed in order to investigate the effect of static load on deformation. It was found that thrust load controls limitations of the bearings, and the deformation by the static load is not the main reason of the adhesion failure.
\end{abstract}

\section{Introduction}

The UHMWPE (Ultra-High-Molecular-WeightPolyethylene) has some good mechanical features such as wear resistance and corrosion resistance. In our previous studies on UHMWPE thrust bearings [1,2], we investigated the effect of thrust load on bearing life in dry air. The failure pattern of these bearings was the thermal deformation. The thermal deformation depended on the thrust load and rotation speed. Furthermore, we studied PEEK, PPS, and PTFE bearings in water [3-6].

The compressive strength of the UHMWPE is lower than that of other engineering plastics. The constant load deforms the UHMWPE samples, and the effect of static load on the deformation of UHMWPE was investigated $[7,8]$. However, the effect of the static load on the life of UHMWPE bearing is unclear.

In this study, the rolling contact fatigue tests were performed in order to investigate the effect of thrust load on life of UHMWPE bearings. Furthermore, the static compression tests were performed in order to investigate the effect of static load on deformation.

\section{Test method}

\subsection{Specimens}

The bearing specimen (two UHMWPE races - one UHMWPE retainer with nine soda glass balls) was designed based on the Japanese Industrial Standards (JIS) B 1512-2 2011 (Rolling bearing - Boundary dimensions Part2: Thrust bearings) and 15131995 (Rolling Bearing Designation, \#51305). Figure 1 is a photograph of the bearing specimen. The outer diameter, the inner diameter and pitch circle diameter were $52 \mathrm{~mm}, 25 \mathrm{~mm}$ and 38.5 $\mathrm{mm}$, respectively. The ball diameter was $9.525 \mathrm{~mm} \mathrm{(3/8}$ inch). Table 1 shows the material properties of UHMWPE.

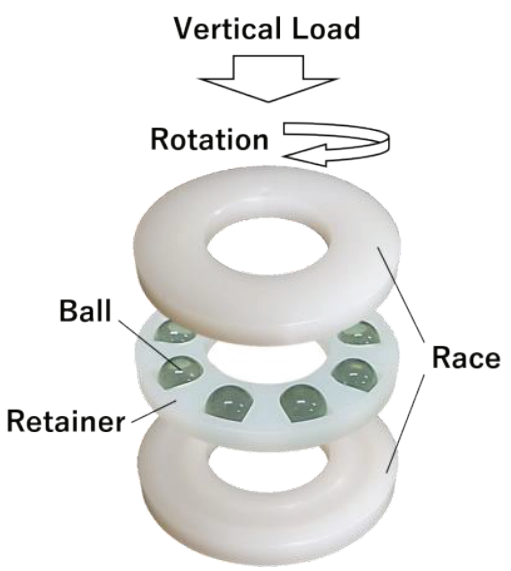

Figure 1. Photograph of UHMWPE thrust bearing.

Table 1. Material properties of UHMWPE $[9,10]$.

\begin{tabular}{c|c|c|c|c}
\hline $\begin{array}{c}\text { Melting } \\
\text { point } \\
{\left[{ }^{\circ} \mathrm{C}\right]}\end{array}$ & $\begin{array}{c}\text { Glass } \\
\text { transition } \\
\text { point }\left[{ }^{\circ} \mathrm{C}\right]\end{array}$ & $\begin{array}{c}\text { Water } \\
\text { absorption } \\
{[\%]}\end{array}$ & $\begin{array}{c}\text { Specific } \\
\text { gravity }\end{array}$ & $\begin{array}{c}\text { Compression } \\
\text { strength } \\
{[\mathrm{MPa}]}\end{array}$ \\
\hline 136 & -20 & $<0.01$ & 0.94 & 19 \\
\hline
\end{tabular}

\subsection{Rolling contact fatigue (RCF) test}

The RCF tests of UHMWPE thrust bearings were done using a RCF test machine which was developed by the Kida's group [3-6]. Figure 2 shows a schematic illustration of the RCF testing machine. All tests were performed in water and total number of cycles was $1.0 \times 10^{6}$. The RCF tests were stopped when the rotating resistance increased rapidly.

\footnotetext{
a Corresponding author: kida@eng.u-toyama.ac.jp
} 


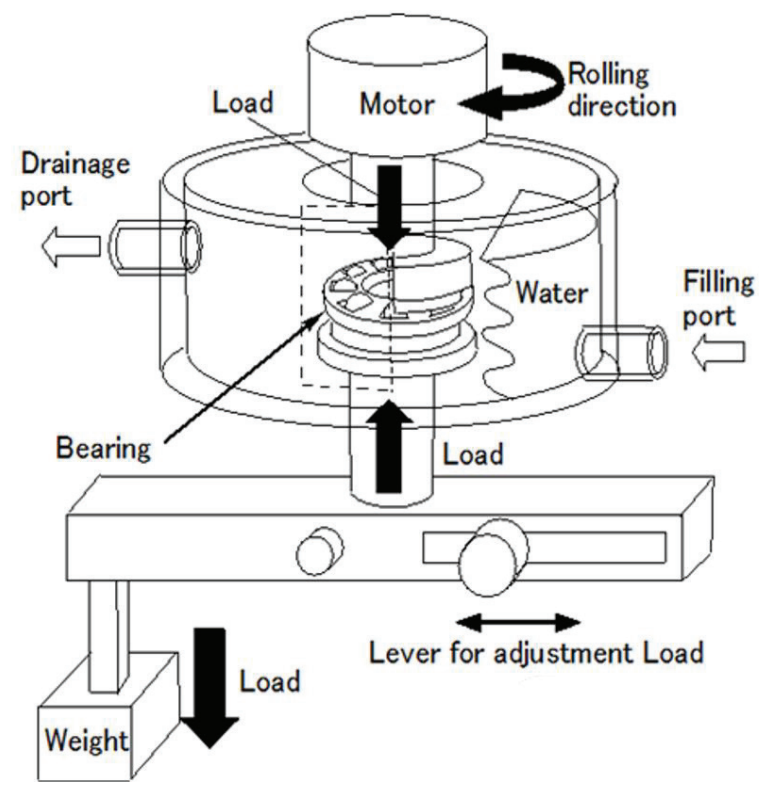

Figure 2. Schematic illustration of RCF testing machine.

\subsection{Static compression (SC) test}

Figure 3 shows a schematic illustration of the static compression testing machine. The ball was pushed by the static load. The displacement is defined as "the deformation length of the specimen's surface". A laser analogue sensor (KEYENCE CORPORATION, IA-030) measured the displacement. All tests were performed for 14 hours. (This value means the operation time during $1.0 \times 10^{6}$ cycles at $\left.1200 \mathrm{rpm}\right)$. The tests were done in water and air. The static loads were 50 N/ball, 100 N/ball, $150 \mathrm{~N} /$ ball, and $200 \mathrm{~N} /$ ball.

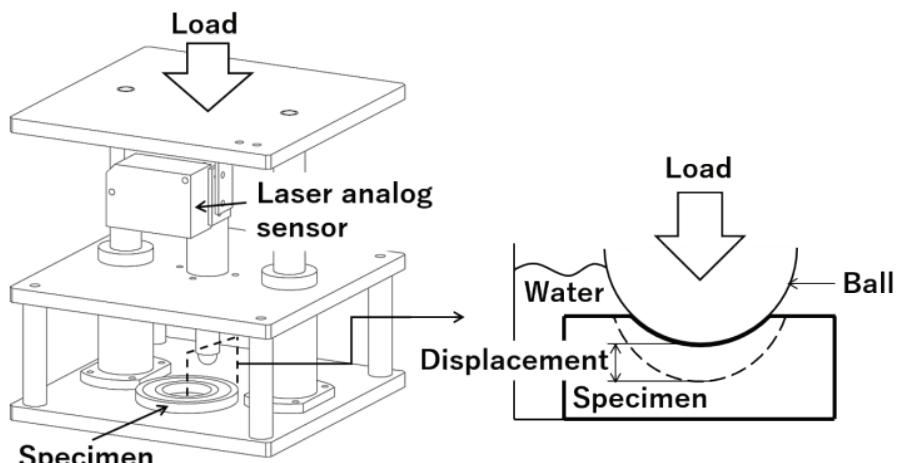

Figure 3. Schematic illustration of RCF testing machine.

\section{Results and discussion}

\subsection{Relation between rotation speed and thrust load}

Figure 4 shows the failure conditions of the specimen. We found two failure patterns: adhesion and indentation. These failures are plotted as " $x$ ". In the case of the adhesion failure, the race adhered to the retainer. This type of failure occurred at $2000 \mathrm{~N}$. In the case of the indentation failure, the specimen did not rotate. The race surface deformed into the ball shape. This type of failure occurred at $3500 \mathrm{~N}$. In addition, no failure was observed on a contact area between the race and the retainer under a load of $2000 \mathrm{~N}$. This indicates the thrust load controls the limitations of the bearings.

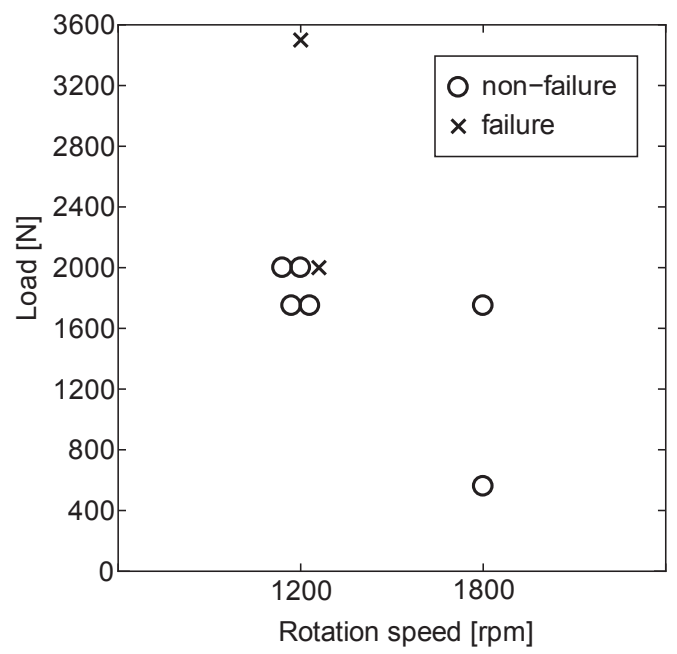

Figure 4. Relation between rotation speed and thrust load.

\subsection{Wear loss}

Figure 5 shows the relation between the wear loss and the thrust load. The wear loss ranged from $-2.8 \mathrm{mg}$ to 20.6 $\mathrm{mg}$. Some values of wear loss are lower than "zero" because the amount of water absorption is higher than the wear loss. This indicates that we can ignore the wear loss in this test.

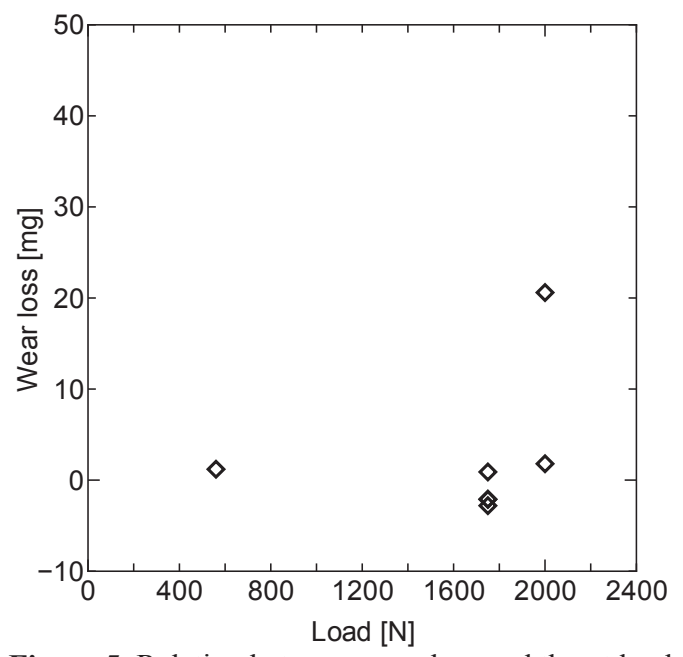

Figure 5. Relation between wear loss and thrust load.

\subsection{Relation between displacement and time}

Figures 6 show the relation between the displacement and the time. Five static compression tests were performed under a load of $50 \mathrm{~N} / \mathrm{ball}$. The average values are plotted as "bold line". The deformation behavior in air was similar to that in water. After 14 hours, the difference of the average of displacement was about $0.01 \mathrm{~mm}$ between air and water conditions. These results indicate the maximum displacement in air is similar to that in water. 


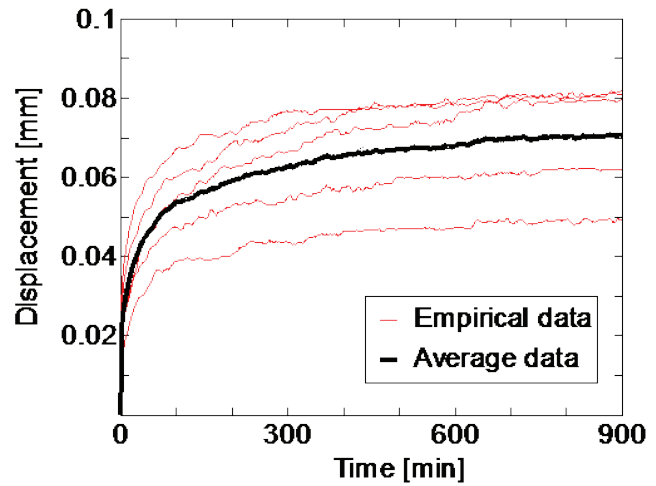

(a) In air.

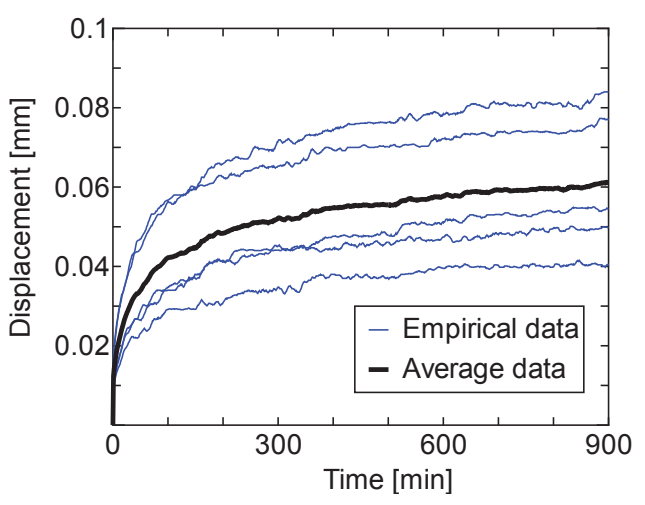

(b) In water.

Figure 6. Relation between displacement and time at $50 \mathrm{~N} / \mathrm{ball}$.

\subsection{Relation between maximum displacements and static loads}

Figure 7 shows the effect of the static load on the maximum displacement in air and water after 14 hours. The SC tests were performed under 50 N/ball, 100 N/ball, $150 \mathrm{~N} / \mathrm{ball}$, and $200 \mathrm{~N} / \mathrm{ball}$. The maximum displacements increase with the load when the load is over $100 \mathrm{~N} / \mathrm{ball}$. The maximum displacement of $200 \mathrm{~N} /$ ball was 0.1269

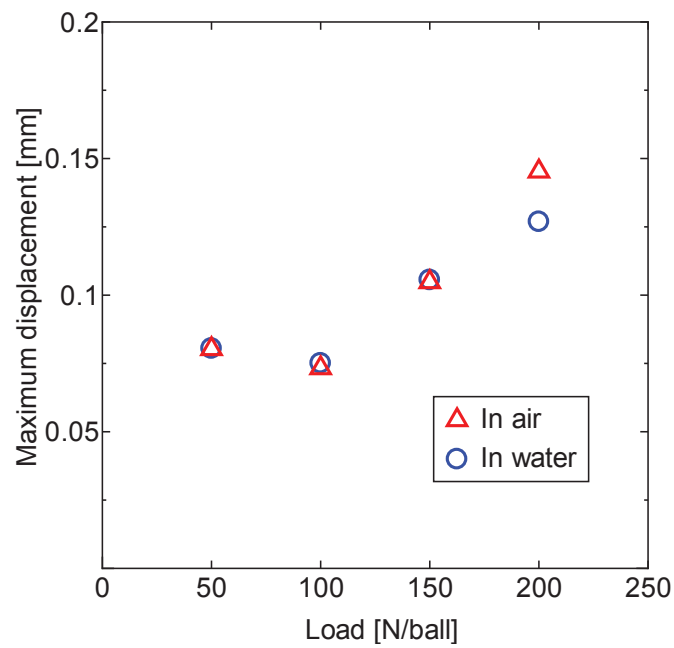

Figure 7. Relation between maximum displacement and static load in air and water. $\mathrm{mm}$ in water. Even in the condition, the race does not contact the retainer. This indicates the static load is not the main cause of the adhesion failure.

\section{Conclusions}

In the present study, RCF tests and SC tests of UHMWPE thrust bearings were performed. The effect of thrust load on life was examined. Furthermore, the effect of static load on the deformation was studied. The following conclusions were obtained:

(1) The thrust load controls the limitations of the bearings.

(2) The failure is not governed by the wear loss.

(3) The maximum displacement after 14 hours in air is similar to that in water.

(4) The static load is not the main cause of the adhesion failure.

\section{References}

1. K. Mizobe, N. Fujimura, Y. Kashima, K. Kida, Key Engineering Materials, 703, 192-196, (2016)

2. S. Hazeyama, S. Oyama, K. Kida, T. Honda, K. Mizobe, H. Koike, K. Itakura, Y. Kashima, K. Kanemasu, Advanced Materials Research, 683, 7781, (2013)

3. M. Orito, K. Kida, Y. Hashizume, M. Ishida, K. Mizobe, Y. Kashima, Materials Science Forum, 878, 117-121, (2016)

4. T. Honda, K. Kida, E. C. Santos, Y. Kashima, K. Kanemasu, Proc. World Tribology Congress, 488, (2009)

5. X. Shi, Y. Kashima, K. Kida, Applied Mechanics and Materials, 563, 270-274, (2014)

6. K. Itakura, T. Honda, S. Oyama, K. Kida, S. hazeyama, Y. Kashima, Advanced Materials Research, 683, 391-395, (2013)

7. F. Metin, M. Cengil, Journal of Achievements in Materials and Manufacturing Engineering, 78(2), $65-$ 70, (2016)

8. F. Quinci, M. Dressler, A. M. Strickland, A. Metcalfe, M. Taylor, G. Limbert, Multifunctional Materials for Tribological Applications, 339-364, (2015)

9. Mitsuboshi Belting Ltd., http://www.mitsuboshi. co.jp/english/

10. NSK Ltd., technical report, http://www.nsk.com/jp 